\title{
ETV6/NTRK3 Fusion Gene
}

National Cancer Institute

\section{Source}

National Cancer Institute. ET V6/NTRK3 Fusion Gene. NCI Thesaurus. Code $C 99413$.

A fusion gene that results from a chromosomal translocation $t(12 ; 15)(p 13 ; q 25)$ which fuses the 5' half of the ETV6 gene to the 3' half of the NTRK3 gene. This fusion is associated with congenital fibrosarcoma, congenital mesoblastic nephroma (cellular and mixed variants), and secretory ductal carcinoma of breast. 